\title{
Effect of ion-implantation-induced defects and Mg dopants on the thermoelectric properties of ScN
}

Tureson, Nina; Marteau, Marc; Cabioch, Thierry; Van Nong, Ngo; Jensen, Jens; Lu, Jun; Greczynski, Grzegorz; Fournier, Daniele; Singh, Niraj; Soni, Ajay

Total number of authors:

13

Published in:

Physical Review B

Link to article, DOI:

10.1103/PhysRevB.98.205307

Publication date:

2018

Document Version

Publisher's PDF, also known as Version of record

Link back to DTU Orbit

Citation (APA):

Tureson, N., Marteau, M., Cabioch, T., Van Nong, N., Jensen, J., Lu, J., Greczynski, G., Fournier, D., Singh, N., Soni, A., Belliard, L., Eklund, P., \& le Febvrier, A. (2018). Effect of ion-implantation-induced defects and Mg dopants on the thermoelectric properties of ScN. Physical Review B, 98(20), [205307].

https://doi.org/10.1103/PhysRevB.98.205307

\section{General rights}

Copyright and moral rights for the publications made accessible in the public portal are retained by the authors and/or other copyright owners and it is a condition of accessing publications that users recognise and abide by the legal requirements associated with these rights.

- Users may download and print one copy of any publication from the public portal for the purpose of private study or research.

- You may not further distribute the material or use it for any profit-making activity or commercial gain

- You may freely distribute the URL identifying the publication in the public portal 


\title{
Effect of ion-implantation-induced defects and Mg dopants on the thermoelectric properties of ScN
}

\author{
Nina Tureson, ${ }^{1}$ Marc Marteau, ${ }^{2}$ Thierry Cabioch,${ }^{2}$ Ngo Van Nong, ${ }^{3}$ Jens Jensen, ${ }^{1}$ Jun Lu, ${ }^{1}$ Grzegorz Greczynski, ${ }^{1}$ \\ Daniele Fournier, ${ }^{4}$ Niraj Singh, ${ }^{5}$ Ajay Soni, ${ }^{5}$ Laurent Belliard, ${ }^{4}$ Per Eklund, ${ }^{1, *}$ and Arnaud le Febvrier ${ }^{1, \dagger}$ \\ ${ }^{1}$ Department of Physics, Chemistry and Biology (IFM), Linköping University, SE-581 83 Linköping, Sweden \\ ${ }^{2}$ Institut PPRIME, Centre National de la Recherche Scientifique, Université de Poitiers-ENSMA, UPR 3346, SP2MI, \\ F-86962 Futuroscope Chasseneuil Cedex, France \\ ${ }^{3}$ Department of Energy Conversion and Storage, Technical University of Denmark, Ris $\phi$ Campus, Fredriksborgsvej 399, \\ Building 779, 4000 Roskilde, Denmark \\ ${ }^{4}$ Sorbonne Université, Centre National de la Recherche Scientifique, Institut des NanoSciences de Paris, UMR 7588, Paris 75005, France \\ ${ }^{5}$ School of Basic Sciences, Indian Institute of Technology Mandi, Mandi, Himachal Pradesh 175005, India
}

(Received 19 July 2018; revised manuscript received 24 September 2018; published 26 November 2018)

\begin{abstract}
For applications in energy harvesting and environmentally friendly cooling, and for power sources in remote or portable applications, it is desired to enhance the efficiency of thermoelectric materials. One strategy consists of reducing the thermal conductivity while increasing or retaining the thermoelectric power factor. An approach to achieve this is doping to enhance the Seebeck coefficient and electrical conductivity, while simultaneously introducing defects in the materials to increase phonon scattering. Here, we use $\mathrm{Mg}$ ion implantation to induce defects in epitaxial $\mathrm{ScN}$ (111) films. The films were implanted with $\mathrm{Mg}^{+}$ions with different concentration profiles along the thickness of the film, incorporating 0.35 to 2.2 at. \% of $\mathrm{Mg}$ in $\mathrm{ScN}$. Implantation at high temperature $\left(600^{\circ} \mathrm{C}\right)$, with few defects due to the temperature, does not substantially affect the thermal conductivity compared to a reference $\mathrm{ScN}$. Samples implanted at room temperature, in contrast, exhibited a reduction of the thermal conductivity by a factor of 3 . The sample doped with 2.2 at. $\%$ of $\mathrm{Mg}$ also showed an increased power factor after implantation. This paper thus shows the effect of ion-induced defects on thermal conductivity of $\mathrm{ScN}$ films. High-temperature implantation allows the defects to be annealed out during implantation, while the defects are retained for room-temperature implanted samples, allowing for a drastic reduction in thermal conductivity.
\end{abstract}

DOI: 10.1103/PhysRevB.98.205307

\section{INTRODUCTION}

Thermoelectric materials and devices are applied for energy harvesting, for converting waste heat (temperature gradients) into useful electricity, as power sources in remote or portable applications using Seebeck effect, and for environmentally friendly cooling using the Peltier effect [1]. The efficiency of a thermoelectric material is connected to the dimensionless thermoelectric figure of merit $\left(Z T=S^{2} \sigma T / \kappa\right)$, which consists of the Seebeck coefficient $(S)$, the electrical conductivity $(\sigma)$, the thermal conductivity $(\mathrm{K})$, and the absolute temperature $(T)$. To enhance the figure of merit of a material, and thus the efficiency, strategic optimizations are required since all parameters $(S, \sigma$, and $\kappa)$ are highly interrelated $[2,3]$.

Different approaches are used for improving $Z T$, including strategies to increase the power factor and reducing the thermal conductivity. Maximizing the power factor includes the search for new materials or optimization of existing ones using approaches such as doping, alloying, and nanoscale effects (e.g., quantum confinement) [4]. Minimizing the thermal conductivity can be achieved by alloying, forming composites,

*Corresponding author: per.eklund@liu.se

${ }^{\dagger}$ Corresponding author: arnaud.le.febvrier@liu.se using naturally poor thermal conductors such as some layered materials, using soft phonon modes, and nanostructuring of the materials [2,3,5-10]. For nanoscale materials, quantum size effects can affect the density of state at the Fermi level $\left(E_{F}\right)$ and thus increase the power factor [5,11]. From bulk (three dimensional) to thin film (two dimensional), the thermal conductivity can be reduced by boundary scattering without reducing the electrical conductivity or power factor. With thin films, similar approaches are used as for bulk materials, and further approaches include superlattices and multilayers [12-15].

In the present paper, we investigate an approach to enhance the power factor of thin films by doping in combination with reduction of the thermal conductivity by the creation of defects (point defects and nanoscale line defects). For doping, we use ion implantation instead of directly introducing the dopants while depositing the material. Ion implantation is a commonly used technique for doping of silicon in the semiconductor industry and is suitable for doping thin films or the surface of bulk materials. It is a method known for precise dose control and good reproducibility as well as a full range of possible implanted elements. Depending on the energy and mass of the implanted ions, different degrees of damage will be induced in the implanted material. Typical collision cascade effects will thus create point defects (vacancies, interstitials, vacancy-interstitial pairs, and antisites) and possibly 
extended defects (dislocations, vacancy clusters, etc.) which can progressively evolve or disappear during annealing. These evolutions are strongly material dependent [16]. In contrast to the semiconductor industry, these defects and imperfections can be an advantage for thermoelectric materials and increase phonon scattering, leading to a reduced thermal conductivity.

As a possible model system to demonstrate this general idea of reducing the thermal conductivity as well as doping by ion implantation, we choose $\mathrm{ScN}$. Several of the semiconducting transition-metal nitrides, in particular $\mathrm{ScN}$ - and $\mathrm{CrN}$ based materials, have recently emerged as promising thermoelectric materials [13,17-22]. ScN has favorable properties such as high carrier mobility $\left(10-180 \mathrm{~cm}^{2} \mathrm{~V}^{-1} \mathrm{~s}^{-1}\right)$, carrier concentration in the range $10^{18}-10^{22} \mathrm{~cm}^{-3}$ [23], low electrical resistivity $(\sim 300 \mu \Omega \mathrm{cm})$ [19], and a narrow indirect band gap of around $0.9 \mathrm{eV}[23,24]$. In comparison with established thermoelectric materials like $\mathrm{PbTe}$ and $\mathrm{Bi}_{2} \mathrm{Te}_{3}$ [2], the power factor of $\mathrm{ScN}\left(2.5-3.3 \mathrm{~W} \mathrm{~m}^{-1} \mathrm{~K}^{-2}\right)[19,25]$ is on the same order of magnitude [19,25-29]. However, the thermal conductivity is relatively high $\left(10-12 \mathrm{~W} \mathrm{~m}^{-1} \mathrm{~K}^{-1}\right)[25,30]$ and needs to be minimized for thermoelectric application. Previous studies have shown different approaches for reducing the thermal conductivity of $\mathrm{ScN}$ [27,30-32]. For example, the thermal conductivity of $\mathrm{ScN}$ was reduced by a factor of 5 using $\mathrm{Nb}$ alloying, but the power factor was degraded, leading to an overall thermoelectric figure of merit similar to that of $\mathrm{ScN}$ [27].

The nature of dopants used in the $\mathrm{ScN}$ system has to be chosen wisely. More than creating defects in the $\mathrm{ScN}$ matrix, the dopant may play an important role on the electronic and/or optical properties of ScN. Kerdsongpanya et al. theoretically demonstrated the influence of introduction of impurities in $\mathrm{ScN}$ on either $\mathrm{N}$ or Sc sites on the density of states around $E_{F}$ [33]. The desired effect for maximizing the Seebeck coefficient of thermoelectric materials is to have a steep slope of the transport distribution function close to $E_{F}$. This can be achieved with the presence of impurities or vacancies in the $\mathrm{ScN}$ matrix which creates a peak close to $E_{F}$ [2,34]. Kerdsongpanya et al. proposed magnesium doping in $\mathrm{ScN}$ to achieve a peak shift towards $E_{F}$ [33]. According to first-principles calculations a few percent of $\mathrm{Mg}$ doping is enough to induce these effects [33]. Mg contents above 3 at. $\%$ shift $E_{F}$ into the valence band, rendering the material $p$ type, as experimentally demonstrated by Saha et al. $[28,35]$. Furthermore, contaminants such as oxygen and fluorine can act as donors in $\mathrm{ScN}$, also leading to a shift of $E_{F}[25,33]$.

In the present paper, epitaxial $\mathrm{ScN}$ thin films were grown using dc reactive magnetron sputtering and then implanted with $\mathrm{Mg}^{+}$ions. Different implantation conditions were tested in order to analyze the influence on the thermoelectric properties of the concentration of dopants but also of the defects created by implantation. A series of samples implanted at room temperature (RT) with different doses from 0 to 2.2 at. $\%$ was used for a complete study with the evolution of the thermoelectric properties with the concentration of dopants implanted with defects. The samples implanted at room temperature with an average concentration of 2.2 at. $\%$ of $\mathrm{Mg}$ exhibited a large decrease in thermal conductivity by $70 \%$ and an increased absolute value of the Seebeck coefficient by $60 \%$. One of the samples was implanted at high temperature
(HT) with 2.2 at. \% of $\mathrm{Mg}$ in order to isolate the effect of magnesium doping since a large fraction of the implantationinduced defects might be annealed during the implantation process at high temperature. The same implantation (2.2 at. $\%$ of $\mathrm{Mg}$ ) performed at room temperature on a $\mathrm{ScN}$ film was used for comparison and for evaluating the effect of irradiation-induced defects on the thermoelectric properties.

\section{EXPERIMENTAL DETAILS}

$\mathrm{ScN}$ thin films were deposited using dc reactive magnetron sputtering in an ultra-high-vacuum chamber (base pressure $\left.10^{-6} \mathrm{~Pa}\right)$ with Sc (50-mm diameter, MaTek: Sc 99.5\%). The sputtering targets were operated with $125 \mathrm{~W}$ under a pressure of $0.27 \mathrm{~Pa}\left(2 \mathrm{mTorr}\right.$ ) in an $\mathrm{Ar} / \mathrm{N}_{2}$ (flow ratio $75 \% \mathrm{Ar}: 25 \%$ $\mathrm{N}_{2}$ ) sputtering-gas mixture. We used $10 \times 10$-mm one sidepolished substrates of $\mathrm{Al}_{2} \mathrm{O}_{3}$ (c-cut) (Alineason Materials \& Technology). The sapphire substrates were kept at a temperature of $800{ }^{\circ} \mathrm{C}$ and under constant rotation during the deposition. Prior to deposition, the substrates were cleaned first for $10 \mathrm{~min}$ in acetone in an ultrasonic bath, then in ethanol, and blown dry with a $\mathrm{N}_{2}$ gun. One sample was selected as a reference (labeled REF), and the other six samples were implanted with $\mathrm{Mg}^{+}$ions. The SRIM 2013 software [36] was used to simulate and determinate the appropriate ion energies and respective doses needed to obtain the desired $\mathrm{Mg}$ concentration in the $\mathrm{ScN}$ film [density of $4.26 \mathrm{~g} / \mathrm{cm}^{3}$ (calculated from the ICDD data 032-0656286)]. Two different profiles for the $\mathrm{Mg}$ concentration were applied: one flat by using five different energies for $\mathrm{Mg}^{+}$ions and one with a Gaussian-like profile along the thickness of the film by using only one energy for implanted ions. The implanted dose of $\mathrm{Mg}$ was adjusted for each energy by controlling the duration of the implantation while maintaining a current beam density not exceeding $5 \mu \mathrm{A} \mathrm{cm}^{-2}$ to avoid a temperature increase of the $\mathrm{ScN}$ films during the implantation process. Table I summarizes the conditions of implantation for the different samples. The first series of samples was implanted at room temperature with different average concentrations of $\mathrm{Mg}[\mathrm{Mg} /(\mathrm{Sc}+\mathrm{N}+\mathrm{Mg})]$ from 0.35 at. \% to a maximum of 2.2 at. \% (labeled RT). Another film was also implanted to obtain 2.2 at. \% of $\mathrm{Mg}$ at a temperature of $600^{\circ} \mathrm{C}$ (labeled HT). Finally, a sample was implanted at room temperature but using only one energy of $150 \mathrm{keV}$ for implanted $\mathrm{Mg}^{+}$(labeled SE for single-energy) with a total dose selected to obtain an average of 2.2 at. \% of $\mathrm{Mg}$ in $\mathrm{ScN}$, but with a Gaussian-like profile. For every implantation, the samples were tilted with an angle of $2-5^{\circ}$ to prevent channeling of the implanted $\mathrm{Mg}$ ions into the epitaxial $\mathrm{ScN}$ thin films.

$\mathrm{X}$-ray-diffraction (XRD) measurements were performed with an X'Pert PRO from PANalytical apparatus for $\theta-2 \theta$ scans using a $\mathrm{Cu} \mathrm{K} \mathrm{K}_{\alpha}$ radiation with a nickel filter. Philips X'Pert-MRD with $\mathrm{Cu} \mathrm{K}_{\alpha}$ radiation was used for the rocking curves and $\phi$ scans. Surface and cross sections of the films were examined by scanning electron microscopy (SEM, LEO Gemini 1550, Zeiss). High resolution scanning transmission electron microscopy (HRSTEM) images were acquired with the Linköping double $\mathrm{C}_{s}$-corrected FEI Titan ${ }^{3}$ $60-300$ operated at $300 \mathrm{kV}$ using a high angle annular dark field (HAADF) detector. Time-of-flight secondary ion mass 
TABLE I. List of the samples with their labels and different conditions of Mg implantation. The thickness of each film is also listed. The average concentration of magnesium is the one deduced from depth XPS profile measurement performed on the sample 2.2 RT and extrapolated to the other samples according the TOF-SIMS measurement. SE denotes single-energy.

Fluence of implanted $\mathrm{Mg}^{+}$ions for the different energies $\left(\times 10^{15}\right.$ ions $\left./ \mathrm{cm}^{2}\right)$

\begin{tabular}{|c|c|c|c|c|c|c|c|c|c|}
\hline Sample label & Average conc. of $\mathrm{Mg}$ (at. \%) & Thickness (nm) & Temperature $\left({ }^{\circ} \mathrm{C}\right)$ & $20 \mathrm{keV}$ & $50 \mathrm{keV}$ & $100 \mathrm{keV}$ & $150 \mathrm{keV}$ & $180 \mathrm{keV}$ & Total \\
\hline $2.2 \mathrm{HT}$ & 2.2 & 410 & $600^{\circ} \mathrm{C}$ & 2.3 & 5.6 & 9 & 6 & 20 & 42.9 \\
\hline 2.2 SE & 2.2 & 330 & Room temperature & & & & 43 & & 43 \\
\hline $2.2 \mathrm{RT}$ & 2.2 & 345 & Room temperature & 2.3 & 5.6 & 9 & 6 & 20 & 42.9 \\
\hline $1.1 \mathrm{RT}$ & 1.1 & 405 & Room temperature & 1.15 & 2.75 & 4.5 & 3 & 10 & 21.4 \\
\hline $0.75 \mathrm{RT}$ & 0.75 & 410 & Room temperature & 0.76 & 1.8 & 3 & 2 & 6.7 & 14.3 \\
\hline $0.39 \mathrm{RT}$ & 0.35 & 435 & Room temperature & 0.38 & 0.9 & 1.5 & 1 & 3.3 & 7.6 \\
\hline REF & 0 & 365 & & & & & & & \\
\hline
\end{tabular}

spectrometry (TOF-SIMS) using a TOF-SIMS V instrument (ION-TOF GmbH, Germany) was used for measuring the $\mathrm{Mg}$ distribution in the implanted films. Dual-beam depth profiling, by alternately applying an analysis beam and a sputter beam (noninterlace), was done in positive mode. This allows selected positive secondary ion species to be monitored as a function of sputter time. A low-energy electron flood gun was applied for charge-compensation during profiling. A quasicontinuous $2.0-\mathrm{keV} \mathrm{O}_{2}{ }^{+}$beam with a current of $670 \mathrm{nA}$ and scanned over $350 \times 350 \mu \mathrm{m}^{2}$ was used as sputter beam. A pulsed $30-\mathrm{keV} \mathrm{Bi}^{+}$beam, cycle time $40 \mu \mathrm{s}$, was used as an analysis beam, with a target current of $3.8 \mathrm{pA}$ and an analysis field of view of $80 \times 80 \mu \mathrm{m}^{2}$ at the center of the sputter craters. Ion mass spectra were acquired, with an extraction voltage of $2000 \mathrm{~V}$ between the sputter sequences, in the so-called spectroscopy mode (bunched 6.5-ns $\mathrm{Bi}^{+}$ion-beam pulse width). SurfaceLab 6 software (version 6.5, ION-TOF $\mathrm{GmbH}$ ) was used for spectra recording and data processing. XPS was performed with an Axis Ultra DLD instrument from Kratos Analytical (UK). The system base pressure during spectra acquisition was $1.1 \times 10^{-9}$ Torr $\left(1.5 \times 10^{-7} \mathrm{~Pa}\right)$. A monochromatic $\mathrm{Al} \mathrm{K} \alpha$ radiation $(h v=1486.6 \mathrm{eV})$ from the source powered to $150 \mathrm{~W}$ was used. Compositional depth profiles were obtained by recording core-level spectra after each sputtering step consisting of 3-min-long bombardment with $4-\mathrm{keV} \mathrm{Ar}^{+}$ions followed by 10-min irradiation at the reduced energy of $0.5 \mathrm{keV}$ to minimize the surface damage and avoid forward implantation of surface species [37]. The $\mathrm{Ar}^{+}$ion beam was incident at the $20^{\circ}$ angle from the surface and rastered over the area of $3 \times 3 \mathrm{~mm}^{2}$. All spectra were collected from the area of $0.3 \times 0.7 \mathrm{~mm}^{2}$ and at normal emission angle. The analyzer pass energy was set to $20 \mathrm{eV}$ which results in the full width at half maximum (FWHM) of $0.55 \mathrm{eV}$ for the $\operatorname{Ag} 3 d_{5 / 2}$ peak. Elemental compositions were determined based on $\mathrm{Sc} 2 p, \mathrm{~N} 1 s, \mathrm{O} 1 s$, and $\mathrm{Mg} 2 s$ peak areas using Casa XPS software (version 2.3.16), and elemental sensitivity factors supplied by Kratos Analytical, Ltd.

Thermal conductivity of the films was obtained at room temperature using modulated thermoreflectance microscopy. In this setup, a pump beam at $532 \mathrm{~nm}$ delivered by a Cobolt MLD laser, intensity modulated by an acousto-optical modulator at a frequency $f$, is focused on the surface of the sample with an objective lens (numerical aperture of 0.5 ). Then, thermal waves were excited in the sample and monitored by the reflectivity surface change recorded around the pump location by another focused laser beam. The specification of the setup is the spatial measurement around the pump beam. We use a 488-nm Oxxius laser to maximize the probe sensitivity to the thermal field on a gold surface. A photodiode and a lock-in amplifier record the ac reflectivity component, in a frequency range between $1 \mathrm{kHz}$ and $1 \mathrm{MHz}$. The measurement of the reflectivity of the probe on the surface is performed along the $x$ axis from -10 to $+10 \mu \mathrm{m}$ around the pump beam area. Figure S1 in the Supplemental Material (SM) [42] represents typical curve of the amplitude and the phase part of the reflectivity signal measured on a gold/substrate and on a gold/film/substrate sample. Finally, the amplitude and phase experimental data were fitted according to a standard Fourier diffusion law to extract the thermal conductivity of the $\mathrm{ScN}$ films [38-41]. A full explanation of the thermal conductivity measurement, fitting, and model used is reported in the SM [42].

The in-plane Seebeck coefficient and the electrical resistivity were measured simultaneously from room temperature to $500{ }^{\circ} \mathrm{C}$ under a low-pressure helium atmosphere $(\sim 9 \times$ $10^{4} \mathrm{~Pa}$, purity $99.999 \%$ with $<0.5$-ppm residual oxygen) using ULVAC-RIKO ZEM3 with a special design for thin films. The substrate contribution to the Seebeck coefficient and electrical resistivity is negligible, and the instrumental error is within $7 \%$. The room-temperature Hall effect measurements up to 5-T magnetic field were performed employing a physical property measurement system (Dynacool).

\section{RESULTS AND DISCUSSION}

XRD $\theta-2 \theta$ scans of as-deposited and Mg-implanted $\mathrm{ScN}$ thin films are presented in Fig. 1(a). The observation of only one diffraction peak from the film demonstrated strong (111) texture of the $\mathrm{ScN}$ thin films. The inset shows the $\mathrm{ScN} 111$ peaks in magnified view around $34.34^{\circ}$. From here, it is evident that no peak shift is observed after the $\mathrm{Mg}$ implantation. The corresponding lattice parameter $4.52 \AA$ is close to earlier reported values [4.50 $\AA$, ICDD PDF 00-045-0978 $(\mathrm{ScN})$ ]. Figure 1(b) shows the evolution of the FWHM of the Rocking curve performed on the 111 reflection of the film. FWHM values vary between $2.4^{\circ}$ and $1.9^{\circ}$ showing that no degradation of the macroscopic view of the crystal quality of the film was noticeable by XRD. The inset shows a $\phi$ scan 

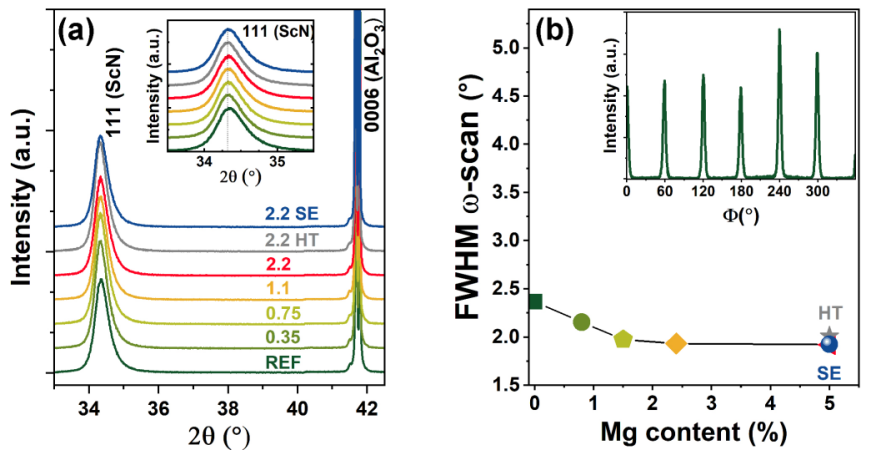

FIG. 1. (a) Offset-separated $\theta-2 \theta$ scans of $\mathrm{ScN}$ film grown on $c$ axis-oriented sapphire substrates. The inset graph shows a closeup of the $\mathrm{ScN} 111$ peak. The numbers in corresponding colors correspond to the average concentration of $\mathrm{Mg}$ in $\mathrm{ScN}$ films. (b) FWHM values of the rocking curve performed on the 111 reflection. The inset shows the $\varphi$ scan $\left(\right.$ at $\left.\psi=70.5^{\circ}\right), \mathrm{ScN}\{111\}$ of the $\mathrm{ScN}$ reference sample grown on sapphire substrate.

of the $\mathrm{ScN}$ reference sample $\left[\chi=70.5^{\circ}, \mathrm{ScN}\{111\}\right]$. The six peaks appear due to twin domain symmetry of $\mathrm{ScN}$ grown on sapphire substrates $[19,27]$. Thus, the films are composed of single phase epitaxial cubic $\mathrm{ScN}$ with an out-of-plane [111] orientation. Due to the low quantity of implantation and the small difference of the ionic radius between $\mathrm{Sc}^{3+}(\mathrm{VI})$ and $\mathrm{Mg}^{2+}(\mathrm{VI})$, it is not possible to discuss a potential substitution of $\mathrm{Mg}$ for Sc by these XRD results.

In Fig. 2, the optical image and the surface morphology from the SEM of the films are shown. No noticeable change of the morphology of the surface of the film has been observed by SEM after implantation of $\mathrm{Mg}$ ions. The nonimplanted $\mathrm{ScN}$ sample has a yellowish color characteristic of $\mathrm{ScN}$ material [43], but the Mg-implanted samples are brown/black. This drastic change of color indicates changes in the band gap with insertion of states or doping [33].

A depth-profile composition analysis of the sample 2.2 RT by x-ray photoelectron spectroscopy gave an average concentration $[\mathrm{Mg} /(\mathrm{Mg}+\mathrm{Sc}+\mathrm{N})]$ around 2.2 at. \% at a plateau (50-300-nm depth) plus a presence of oxygen at 9 at. \% (see SM, Fig. S6 [42]). Even with a base pressure of $6 \times 10^{-8}$ torr, oxygen incorporation at the level of several atomic percent in $\mathrm{ScN}$ occurs due to the high reactivity of Sc with oxygen from residual water during deposition [18,32,33,44-48]. Gregoire et al. demonstrated an occupancy of oxygen on the nitrogen site possible from 2 to 6 at. \% which corresponds at a maximum to $\mathrm{Sc}_{0.94}\left(\mathrm{~N}_{0.94} \mathrm{O}_{0.06}\right)$ [32]. A higher presence of oxygen in the film leads to the accumulation of oxygen at the grain boundaries and defects [18]. In the present paper, the most probable case is an incorporation of oxygen at the level of a few atomic percent in the $\mathrm{Sc}_{1-x} \mathrm{Mg}_{x} \mathrm{~N}_{1-y} \mathrm{O}_{y}(0<y<0.06)$ and $\mathrm{Sc}_{2} \mathrm{O}_{3}$ at the grain boundaries/defects at a few percent $(\leqslant 2 \mathrm{~mol} \%$ ) (more details can be found in the SM, Fig. S7 [42]). This sample with an average of 2.2 at. \% of $\mathrm{Mg}$ was used as reference in order to calculate the percentage of magnesium in each film from the $\mathrm{Mg}^{+}$signal intensity detected by TOF-SIMS. It is important to note that the oxygen content does not affect the purpose of the present paper, as these oxygen contaminations only

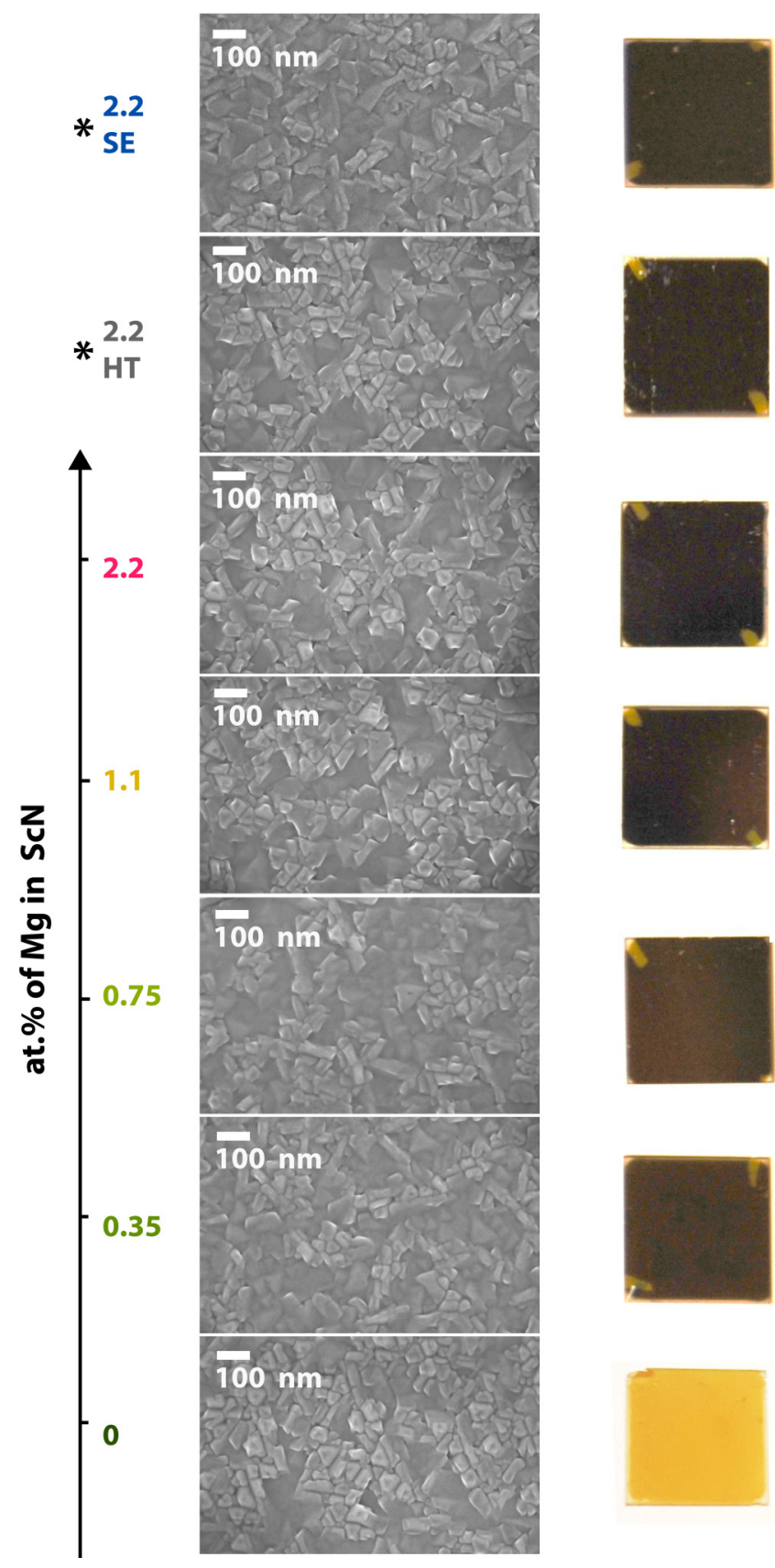

FIG. 2. The morphology of the Mg-implanted $\mathrm{ScN}$ films observed by SEM. To the right, the optical appearance of the films is presented. The numbers to the left indicate the amount of implanted $\mathrm{Mg}$ in the ScN films.

marginally affect the thermal conductivity [49]. However, oxygen doping acts as donor doping and leads to a shift $E_{F}$ towards the conduction band [25,33]. Thus, we do not obtain $p$-type $\mathrm{Mg}$-doped $\mathrm{ScN}$, as in the work of Saha et al. [28,35].

From the SRIM simulations, a depth profile of the implanted $\mathrm{Mg}$ ions in $\mathrm{ScN}$ thin films can be calculated. Figure 3(a) shows how several implantation energies have been used to obtain an approximately constant concentration of magnesium in the $\mathrm{ScN}$ film. Figure 3(b) gives the $\mathrm{Mg}$ profile from only one implantation energy $(150 \mathrm{keV})$, with a total dose of $\mathrm{Mg}$ equivalent as for the $2.2 \mathrm{RT}$ 

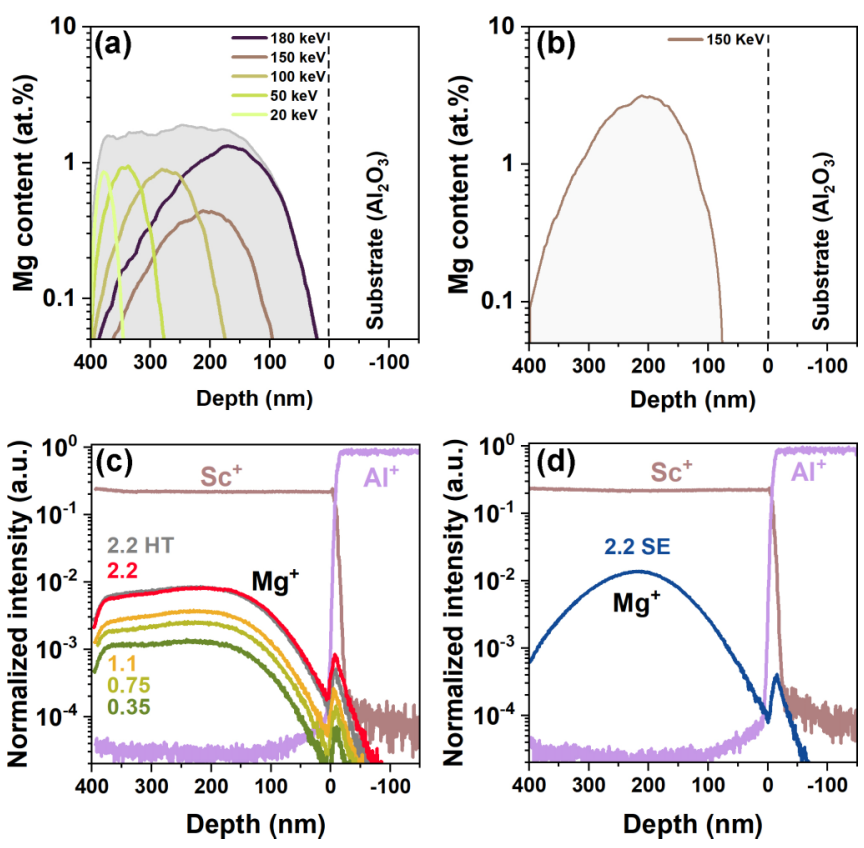

FIG. 3. (a) Simulation results of $\mathrm{Mg}$ implantation in $\mathrm{ScN}$ using SRIM. Different implantation energies and fluencies were used for a flat $\mathrm{Mg}$ profile in the $\mathrm{ScN}$ film. The presented graph is based on the 2.2 RT sample. (b) Simulation of the single-energy implantation (150 keV for the sample $2.2 \mathrm{SE}$ ). (c, d) TOF-SIMS profiles of selected ions for the different implanted films.

sample. A maximum of around 3 at. \% was expected at $\sim 200 \mathrm{~nm}$ from the surface of the sample [Fig. 3(b)]. The Mg profiles measured with TOF-SIMS are presented in Figs. 3(c) and 3(d). Since the thin films have slightly different thicknesses, the film depths were normalized according to the film/substrate interface in order to facilitate comparison. The intensities were also normalized to the substrate signal $\left(\mathrm{Al}^{+}\right)$.
The $\mathrm{ScN}$ reference sample had no detectable $\mathrm{Mg}^{+}$signal. The $\mathrm{Mg}^{+}$signal measured on the flat-profile-implanted samples is slightly lower at the surface of the film, but then almost flat until it drops close to the substrate interface. The intensity of the $\mathrm{Mg}^{+}$signal is consistent with a higher concentration of magnesium in the film. We note that the samples implanted at high temperature (2.2 HT) and at room temperature (2.2 RT) have the same elemental depth profile features (profile and intensity). A variation of the concentration of $\mathrm{Mg}$ is observed along the thickness with a maximum observed at half of the thickness ( $200 \mathrm{~nm})$ and, almost symmetrically, a decrease of $\mathrm{Mg}$ concentration up to the surface and the film/substrate interface. The profiles throughout the film appear relatively similar for all samples and match the profiles from the SRIM simulations. The small increase of the $\mathrm{Mg}^{+}$signal appearing at the interface between film and substrate is due to different $\mathrm{Mg}^{+}$yield in $\mathrm{ScN}$ and $\mathrm{Al}_{2} \mathrm{O}_{3}$.

Figure 4 shows HAADF-HRSTEM images of the $\mathrm{ScN}$ reference sample, the 2.2 RT sample and 2.2 HT sample where two columnar grains and the grain boundary between them can be observed for both samples. Local fast Fourier transforms (FFTs) were performed on the different zones marked in the corresponding micrograph. Very similar comments can be addressed for the reference sample (before implantation) [Fig. 4(a)] and the high-temperature-implanted sample (2.2 HT) [Fig. 4(c)]. They both present a high level of ordering and homogeneity inside the grains with sharp spots on local FFT. In other words, these observations did not allow for identification of defects inside the grains which could have formed during the growth process or during the $\mathrm{Mg}$ implantation at $600^{\circ} \mathrm{C}$. In the case of the room-temperature-implanted sample, the high degree of ordering of the atoms is visible in some parts of the columnar grains and this is confirmed by the sharp spots on the local FFT [see areas 1 and 2 in Fig. 4(b)]. Blurry and likely defect-rich areas, with a typical size of 10 $\mathrm{nm}$, are distinguishable as well as a broadening of the spot
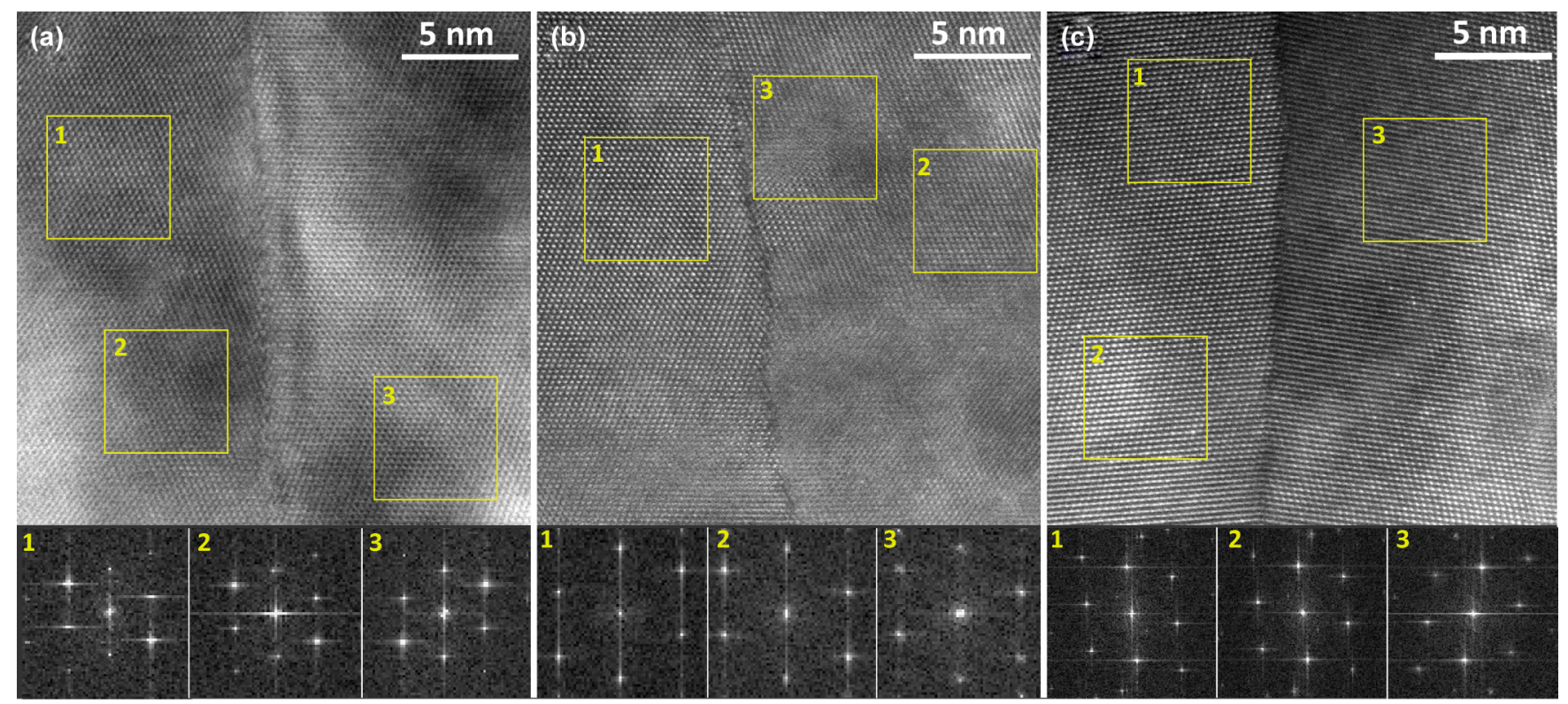

FIG. 4. HRSTEM micrograph with the HAADF detector of the ScN Ref sample (a), the 2.2 RT sample (b), and the 2.2 HT sample (c). Below each image, the local FFT of the corresponding zone is marked on the image. 

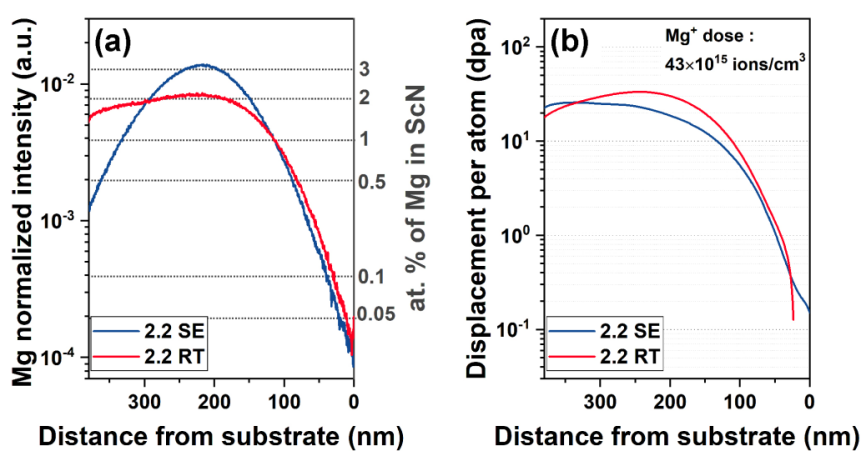

FIG. 5. Comparison between film implanted with one energy (2.2 SE) or five energies of implantation (2.2 RT). (a) TOF-SIMS profile of $\mathrm{Mg}$ ions and the estimated atomic percent of $\mathrm{Mg}$ in $\mathrm{ScN}$ along the thickness of the film. (b) SRIM simulation of the recoil concentration (displacement per atoms) $(\mathrm{Sc}+\mathrm{N})$ with a total dose of $\mathrm{Mg}^{+}$of $43 \times 10^{15}$ ions $/ \mathrm{cm}^{3}$.

on their local FFT (area 3). The HRSTEM analysis illustrates the difference between the room-temperature implantation and high-temperature implantation of $\mathrm{ScN}$. By implanting the magnesium at $600{ }^{\circ} \mathrm{C}$, the thermal energy during implantation appears to be sufficient to anneal out most of the defects induced by implantation. In contrast, at room temperature, the defects and local misalignment of atoms exist within the grains.

Figure 5(a) is a closer comparison of the TOF-SIMS analysis of the 2.2 RT and 2.2 SE samples. Both samples had a similar substrate/film interface up to 100-150-nm thickness. At a distance between 150 and $300 \mathrm{~nm}$, the $2.2 \mathrm{SE}$ had a higher atomic percent of $\mathrm{Mg}$ (3 at. \% locally) than the 2.2 RT. Close to the surface, the $2.2 \mathrm{SE}$ had a lower atomic percent of $\mathrm{Mg}$ than 2.2 RT down to a negligible amount of $\mathrm{Mg}$ at the top surface of the film. Figure 5(b) represents the evolution of total atom displacement [recoil expressed in displacement per atom (DPA)] of Sc and $\mathrm{N}$ simulated by SRIM in a case of multienergy and a single-energy implantation aiming for a total dose of $43 \times 10^{15}$ ions $/ \mathrm{cm}^{2}$. The two simulated curves show a similar quantity and distribution of displacement per atom ( 20-30 DPA) and thus defects induced by the implantation. In terms of composition, the $2.2 \mathrm{RT}$ and 2.2 SE samples differed with different profiles of $\mathrm{Mg}$ along the thickness. Nevertheless, in terms of total displacement

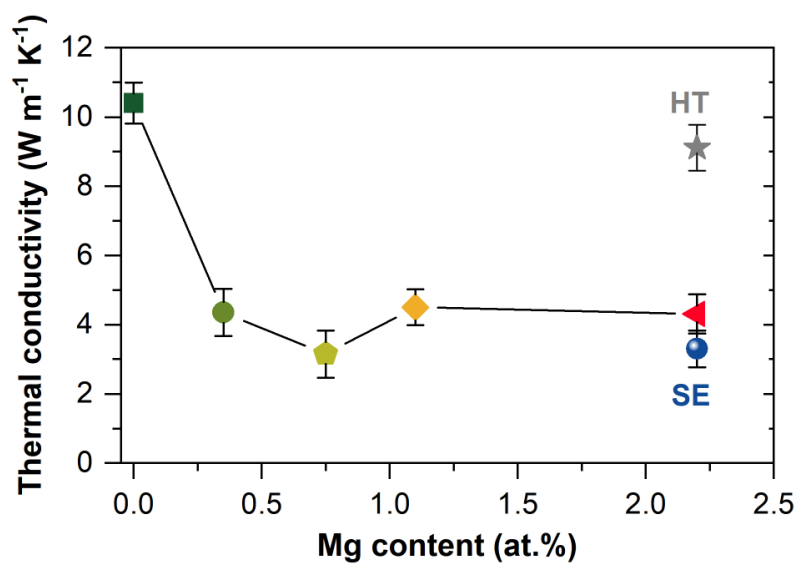

FIG. 6. The thermal conductivity values of the different alloys obtained by fitting of the modulated thermoreflectance microscopy measurements. Model: $250-\mathrm{nm}$ gold $\left(k=225 \mathrm{~W} \mathrm{~m}^{-1} \mathrm{~K}^{-1} ; D=\right.$ $\left.0.9 \times 10^{-4} \mathrm{~m}^{2} \mathrm{~s}^{-1}\right) / \mathrm{Mg}-\mathrm{ScN}$ film on $\mathrm{Al}_{2} \mathrm{O}_{3}\left(k=46 \mathrm{~W} \mathrm{~m}^{-1} \mathrm{~K}^{-1}\right.$; $D=1.48 \times 10^{-5} \mathrm{~m}^{2} \mathrm{~s}^{-1}$ ).

per atom and total induced defects, the 2.2 RT and 2.2 SE films were essentially identical with an average displacement per atom evaluated at $19 \mathrm{DPA}$ for the sample 2.2 RT and 20 DPA for the 2.2 SE. The different results from TOF-SIMS, HRSTEM, and SRIM simulation are summarized in Table II.

Figure 6 shows the thermal conductivity of the Mgimplanted $\mathrm{ScN}$ films. The value of the thermal conductivity of the $\mathrm{ScN}$ reference sample is similar to earlier reported values for $\mathrm{ScN}$ thin films $\left(10-12 \mathrm{~W} \mathrm{~m}^{-1} \mathrm{~K}^{-1}\right)[25,27,30,48]$. The sample implanted at high temperature exhibits a thermal conductivity similar to the value of the reference sample $\mathrm{ScN}$. With a temperature high enough to anneal out the defects, the difference is within the error bars and can thus be considered negligible in this case. The smaller or negligible effect of $\mathrm{Mg}$ dopants on thermal conductivity compared to the one observed in previous study with $\mathrm{Nb}$ doping can be explain by a lower difference of atomic mass between Sc (44.95 u) and $\mathrm{Mg}$ (24.31 u) compared with Sc and Nb (92.20 u) [27].

For room-temperature implantation, a trend of decreasing thermal conductivity for a higher amount of implanted $\mathrm{Mg}$ is clear. A large drop between the $\mathrm{ScN}$ reference $\left(10.5 \mathrm{~W} \mathrm{~m}^{-1} \mathrm{~K}^{-1}\right)$ and the sample implanted with 0.37 at. $\%$ of $\mathrm{Mg}\left(4.2 \mathrm{~W} \mathrm{~m}^{-1} \mathrm{~K}^{-1}\right)$ can be seen. The other implanted

TABLE II. The different characteristics of the sample after ion implantations: concentration of dopant and induced defects with their depth profile and average DPA.

\begin{tabular}{|c|c|c|c|c|c|}
\hline Sample label & \multicolumn{2}{|c|}{ Dopants } & \multicolumn{3}{|c|}{ Defects } \\
\hline $2.2 \mathrm{HT}$ & 2.2 & "Flat" & $600{ }^{\circ} \mathrm{C}$ & & \\
\hline 2.2 SE & 2.2 & Gaussian-like peak & Room temperature & Yes & 20 \\
\hline 2.2 RT & 2.2 & "Flat" & Room temperature & Yes & 19 \\
\hline $0.39 \mathrm{RT}$ & 0.35 & "Flat" & Room temperature & Yes & 3.3 \\
\hline REF & 0 & & & & \\
\hline
\end{tabular}




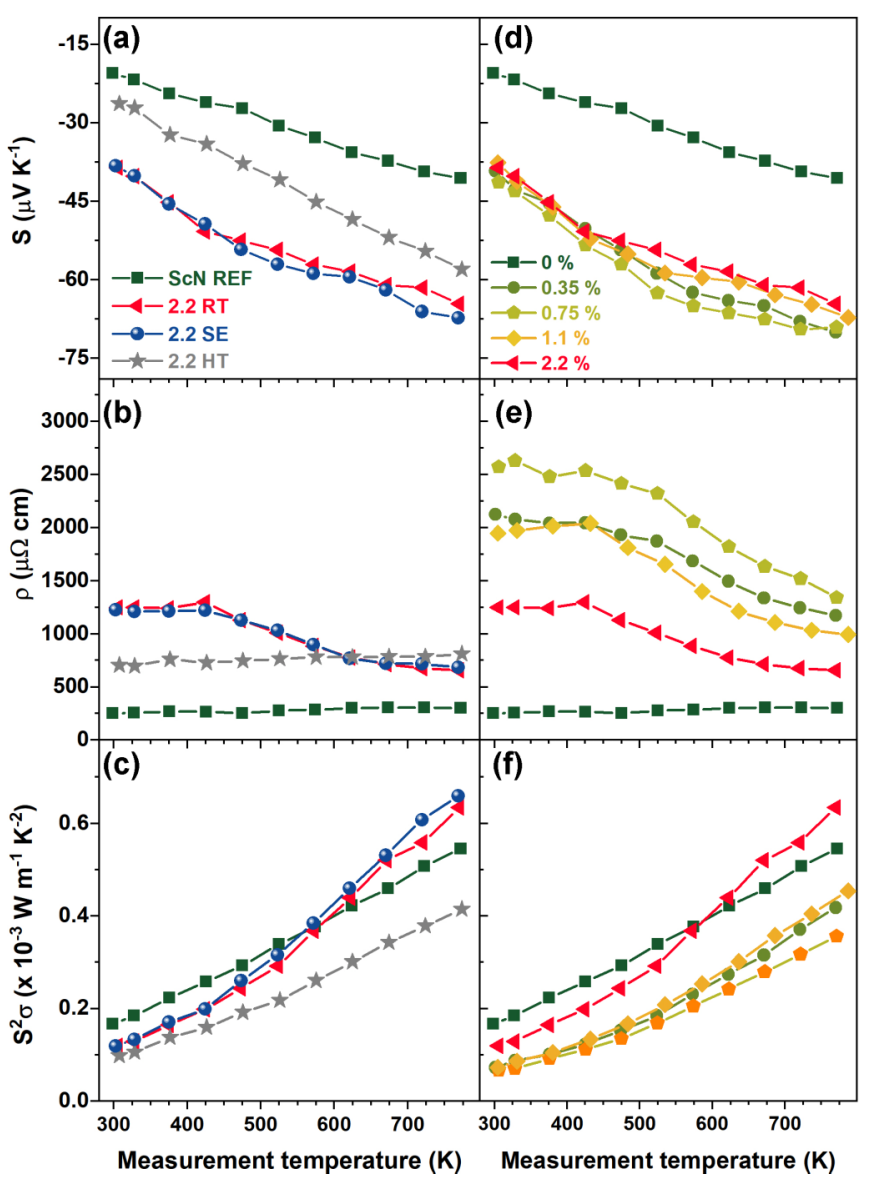

FIG. 7. The measured Seebeck coefficient $(S)$, the electrical resistivity $(\rho)$, and the power factor $\left(S^{2} \sigma\right)$ from room temperature to $770 \mathrm{~K}$ of (a)-(c) the reference sample, the 2.2 SE, the 2.2 RT, and the $2.2 \mathrm{HT}$ and (d)-(f) the samples implanted at room temperature with different concentrations of $\mathrm{Mg}$.

samples at room temperature and using multienergy implantation have similarly low values of the thermal conductivity as the 0.37 RT sample. A minimum is observed for 0.75 at. $\%$ of $\mathrm{Mg}$ in $\mathrm{ScN}$ with a thermal conductivity of $3.2 \mathrm{~W} \mathrm{~m}^{-1} \mathrm{~K}^{-1}$. The sample implanted using a single beam energy also has a similar thermal conductivity, comparable to the lowest observed with a flat $\mathrm{Mg}$ concentration profile.

This large decrease in thermal conductivity (2.5 times lower) for $\mathrm{ScN}$ when implanting a small amount of $\mathrm{Mg}$ may be explained by the increased level of phonon scattering due to the presence of defects induced by ion implantation. The single-energy implanted sample did not show a substantially different thermal conductivity in comparison to the multienergy implanted samples. Thus, the $\mathrm{Mg}$ concentration profile along the thickness of the film does not substantially affect the thermal conductivity of the film. In summary, these results indicate that room-temperature $\mathrm{Mg}$ implantation is preferred if a lower thermal conductivity is desired, to avoid annealing out the defects and retaining the corresponding phonon scattering.

The results of simultaneous measurements of the Seebeck coefficient and the electrical resistivity together with their corresponding power factor are shown in Fig. 7. Figures 7(a)-7(c) present the results from the 2.2 at. $\%$ of $\mathrm{Mg}$ sample with three different conditions (RT, HT, and SE) plus the as deposited $\mathrm{ScN}$ reference sample. In Figs. 7(d)-7(f), the results from the samples with different $\mathrm{Mg}$ concentrations are presented. The Seebeck coefficient, the electrical resistivity, and the power factor at certain fixed temperatures as a function of $\mathrm{Mg}$ concentration and type of implantation are presented in Fig. S9 of the SM [42].

The $\mathrm{ScN}$ reference film is also plotted showing the lowest absolute value of the Seebeck coefficient $(-41 \mu \mathrm{V} / \mathrm{K}$ at $775 \mathrm{~K})$. The film implanted at high temperature (5\% HT), considered here as "defect-free," exhibited an absolute value of the Seebeck coefficient slightly higher than the $\mathrm{ScN}$ reference sample mentioned above $(-56 \mu \mathrm{V} / \mathrm{K}$ at $775 \mathrm{~K})$. The trend of increasing the Seebeck coefficient predicted from density functional theory calculations [33] is corroborated by the results obtained from these experiments. Implantation at room temperature led to samples exhibiting higher absolute values of the Seebeck coefficient up to around $-67 \mu \mathrm{V} / \mathrm{K}$ (775 K). The $\mathrm{Mg}$ concentration profile does not seem to affect the Seebeck coefficient with similar behavior with the temperature for the 2.2 SE. The evolution of the Seebeck coefficient values with the concentration of dopants is low with a maximum absolute value obtained for the sample with 0.75 at. $\%$ of $\mathrm{Mg}(-69 \mu \mathrm{V} / \mathrm{K}$ at $775 \mathrm{~K})$. The results from the Seebeck coefficient measurements show at first an effect of the magnesium doping with an increase of the Seebeck values and secondly combining with the creation of defect (point and/or extended defects) another increase of the Seebeck coefficient values.

The lowest electrical resistivity value is observed for the $\mathrm{ScN}$ reference sample $(\sim 250 \mu \Omega \mathrm{cm})$. This sample exhibited almost a constant electrical resistivity value over the whole measured temperature range. The sample implanted at high temperature (2.2 HT) exhibited a temperature dependence of the electrical resistivity $[\rho(T)]$ similar to the $\mathrm{ScN}$ reference, but with higher values $(\sim 750 \mu \Omega \mathrm{cm})$. Similar to the Seebeck coefficient, no differences are observed between the multienergy and the single-energy implanted films. For all the samples implanted at room temperature, a trend of starting with almost constant resistivity values can be observed, but then a decrease after around $450 \mathrm{~K}$. This change of resistivity may be due to recombination of some point defects (such as Frenkel defects). These point defects can recombine at low temperature (a few hundred degrees Kelvin) and can lead to the creation of extended defects in the materials (line defects such as dislocations or twins). The removal of defects after implantation differs between materials. In the case of silicon, the most studied material for ion implantation, a complete removal of the extended defects can be achieved only at high temperature such as $1100-1300 \mathrm{~K}$ [50]. In our case, one can propose that the measurement temperature is insufficient too to anneal the extended defects present before the measurement and/or created by point-defect recombination during the measurements. The temperature-dependent resistivity from $70 \mathrm{~K}$ to room temperature is presented in the SM [42] (Fig. S8) where differences between the reference sample and the $2.2 \mathrm{RT}$ can be observed due to the mobility of the charge carrier which is affected by the defects induced during implantation. The resistivity values differ slightly with the concentration 
of $\mathrm{Mg}$. In the temperature range of measurement, the sample with 0.75 at. $\%$ of $\mathrm{Mg}$ exhibited the highest values of electrical resistivity and the sample with 2.2 at. \% of $\mathrm{Mg}$ implanted at room temperature exhibited the lowest. The increase of the electrical resistivity can be due to a small contribution of $\mathrm{Mg}$ insertion into $\mathrm{ScN}$ film observed in the 2.2 HT sample and an important contribution from the defects created by ion bombardment [51].

The combination of the Seebeck coefficient and the electrical conductivity for the $\mathrm{ScN}$ reference sample gives the power factor $\sim 0.55 \times 10^{-3} \mathrm{~W} \mathrm{~m}^{-1} \mathrm{~K}^{2}$ at $775 \mathrm{~K}$. The sample implanted at high temperature exhibited a lower power factor than the $\mathrm{ScN}$ reference sample as well as the samples implanted with a low amount of magnesium (0.35 to 1.1 at. $\%)$. The samples with 2.2 at. \% implanted using a single energy and multiple energies exhibited the highest power factor $0.64 \times 10^{-3} \mathrm{~W} \mathrm{~m}^{-1} \mathrm{~K}^{2}$ (at $775 \mathrm{~K}$ ).

The lower (absolute) value of the Seebeck coefficient for $\mathrm{ScN}$ compared to earlier reported $\mathrm{ScN}$ films is most likely due to the higher amount of oxygen contamination present in the film, especially the presence of oxide at grain boundaries and/or defects $[18,19,32,48]$. A presence of oxide at grain boundaries/defects affected the thermoelectric properties with a reduced Seebeck and electrical conductivity resulting in a low power factor $[18,27]$.

Saha et al. reported on the electrical, carrier concentration, and Seebeck coefficient of $\mathrm{Sc}_{1-x} \mathrm{Mg}_{x} \mathrm{~N}$ films grown by dcmagnetron cosputtering $[28,35]$. They reported an increase of electrical resistivity, a decrease of the mobility, and roomtemperature Seebeck values between -50 and $-100 \mu \mathrm{V} / \mathrm{K}$ when doping with $\mathrm{Mg}$. They also reported a switch from $n$ type to $p$-type behavior for film with $x>0.028$. In the present paper, the film contained a higher amount of oxygen and, within the doping range of the paper, only $n$-type behavior was observed. As previously mentioned, the doping by magnesium in $\mathrm{ScN}$ shifts $E_{F}$ towards the valence band, but oxygen doping $\mathrm{ScN}$ leads to a shift towards the conduction band [25,33]. The higher oxygen contamination in the present paper than in the work of Saha et al. thus explains why the $n$-type behavior is retained also for higher concentration of magnesium in $\mathrm{ScN}$ [28,35].

$\mathrm{Mg}$ doping in $\mathrm{ScN}$ with a low amount of defects, achieved by high-temperature ion implantation, yielded a similar thermal conductivity as the $\mathrm{ScN}$ reference and lower power factor due to a higher electrical resistivity. However, implantation of magnesium at room temperature with a constant or Gaussianlike distribution of $\mathrm{Mg}$ along the thickness led to samples exhibiting different physical properties. Implantation at room temperature will create point defects and extended defects which play an important role in the conduction of phonons and charge carriers (electrons or holes). Three features can be emphasized here after implantation of $\mathrm{Mg}$ : a decrease of the thermal conductivity, an increase of the absolute value of the Seebeck coefficient, and an increase of the resistivity and a different $\rho(T)$.

\section{CONCLUSIONS}

Ion implantation was used to implant $\mathrm{Mg}$ in order to induce doping and defects in epitaxial $\mathrm{ScN}$ (111) films grown on sapphire substrates using reactive dc magnetron sputtering. $\mathrm{Mg}^{+}$ions were implanted with different concentration profiles along the thickness of the film. The ion implantations of 0.3 to 2.2 at. $\%$ of $\mathrm{Mg}$ in $\mathrm{ScN}$ did not affect the rock-salt $\mathrm{ScN}$ crystal structure nor morphology of the films. A high temperature of implantation tends to anneal the defects, while doping did not alter the thermal conductivity in comparison to a $\mathrm{ScN}$ reference $\left(\approx 10 \mathrm{~W} \mathrm{~m}^{-1} \mathrm{~K}^{-1}\right)$. In contrast, the roomtemperature-implanted samples exhibited large reduction in thermal conductivity to values close to $3.2 \mathrm{~W} \mathrm{~m}^{-1} \mathrm{~K}^{-1}$ and an increase of the power factor is also observed for the sample with 2.2 at. \% of $\mathrm{Mg}$ compared to the $\mathrm{ScN}$ reference samples. Thus, this paper showed the importance of ion-induced defects in the material on the thermal conductivity, in that hightemperature implantation allows the defects to be annealed out during implantation, while the defects are retained for room-temperature implanted samples, allowing for a drastic reduction in thermal conductivity.

\section{ACKNOWLEDGMENTS}

The authors acknowledge funding from the European Research Council under the European Community's Seventh Framework Programme (FP7 2007-2013) Grant No. 335383, the Swedish Foundation for Strategic Research through the Future Research Leaders 5 program, the Swedish Research Council under Project No. 2016-03365, the Knut and Alice Wallenberg Foundation through the Wallenberg Academy Fellows program, and the Swedish Government Strategic Research Area in Materials Science on Functional Materials at Linköping University (SFO-Mat-LiU Faculty Grant No. 2009 00971). A.S. would like to acknowledge DAE-BRNS [Project No. 37(3)/14/02/2015/BRNS] and IIT Mandi for research facilities.
[1] J. He and T. M. Tritt, Science 357, eaak9997 (2017).

[2] J. R. Sootsman, D. Y. Chung, and M. G. Kanatzidis, Angew. Chem. Int. Ed. 48, 8616 (2009).

[3] G. J. Snyder and E. S. Toberer, Nat. Mater. 7, 105 (2008).

[4] J. Mao, Z. Liu, and Z. Ren, Npj Quantum Materials 1, 16028 (2016).

[5] G. Chen, M. S. Dresselhaus, G. Dresselhaus, J. P. Fleurial, and T. Caillat, Int. Mater. Rev. 48, 45 (2003).

[6] Y. Lan, A. J. Minnich, G. Chen, and Z. Ren, Adv. Funct. Mater. 20, 357 (2010).
[7] Q. Zhang, X. Ai, L. Wang, Y. Chang, W. Luo, W. Jiang, and L. Chen, Adv. Funct. Mater. 25, 966 (2015).

[8] S. K. Bux, R. G. Blair, P. K. Gogna, H. Lee, G. Chen, M. S. Dresselhaus, R. B. Kaner, and J.-P. Fleurial, Adv. Funct. Mater. 19, 2445 (2009).

[9] J. Yang, L. Xi, W. Qiu, L. Wu, X. Shi, L. Chen, J. Yang, W. Zhang, C. Uher, and D. J. Singh, Npj Computational Materials 2, 15015 (2016).

[10] S. Acharya, J. Pandey, and A. Soni, Appl. Phys. Lett. 109, 133904 (2016). 
[11] L. D. Hicks, T. C. Harman, and M. S. Dresselhaus, Appl. Phys. Lett. 63, 3230 (1993).

[12] J. P. Heremans, M. S. Dresselhaus, L. E. Bell, and D. T. Morelli, Nat. Nano 8, 471 (2013).

[13] P. Eklund, S. Kerdsongpanya, and B. Alling, J. Mater. Chem. C 4, 3905 (2016).

[14] R. Venkatasubramanian, E. Siivola, T. Colpitts, and B. O’Quinn, Nature (London) 413, 597 (2001).

[15] B. Saha, A. Shakouri, and T. D. Sands, Appl. Phys. Rev. 5, 021101 (2018).

[16] G. H. Kinchin and R. S. Pease, Rep. Prog. Phys. 18, 1 (1955).

[17] C. X. Quintela, J. P. Podkaminer, M. N. Luckyanova, T. R. Paudel, E. L. Thies, D. A. Hillsberry, D. A. Tenne, E. Y. Tsymbal, G. Chen, C.-B. Eom, and F. Rivadulla, Adv. Mater. 27, 3032 (2015).

[18] P. V. Burmistrova, D. N. Zakharov, T. Favaloro, A. Mohammed, E. A. Stach, A. Shakouri, and T. D. Sands, J. Mater. Res. 30, 626 (2015).

[19] S. Kerdsongpanya, N. V. Nong, N. Pryds, A. Žukauskaitè, J. Jensen, J. Birch, J. Lu, L. Hultman, G. Wingqvist, and P. Eklund, Appl. Phys. Lett. 99, 232113 (2011).

[20] C. X. Quintela, F. Rivadulla, and J. Rivas, Appl. Phys. Lett. 94, 152103 (2009).

[21] C. X. Quintela, B. Rodríguez-González, and F. Rivadulla, Appl. Phys. Lett. 104, 022103 (2014).

[22] F. Arnaud le, N. Ngo Van, A. Gregory, and E. Per, Appl. Phys. Express 11, 051003 (2018).

[23] J. M. Gregoire, S. D. Kirby, G. E. Scopelianos, F. H. Lee, and R. B. van Dover, J. Appl. Phys. 104, 074913 (2008).

[24] H. A. Al-Brithen, A. R. Smith, and D. Gall, Phys. Rev. B 70, 045303 (2004).

[25] P. V. Burmistrova, J. Maassen, T. Favaloro, B. Saha, S. Salamat, Y. Rui Koh, M. S. Lundstrom, A. Shakouri, and T. D. Sands, J. Appl. Phys. 113, 153704 (2013).

[26] B. Saha, T. D. Sands, and U. V. Waghmare, J. Appl. Phys. 109, 083717 (2011).

[27] N. Tureson, N. V. Nong, D. Fournier, N. Singh, S. Acharya, S. Schmidt, L. Belliard, A. Soni, A. 1. Febvrier, and P. Eklund, J. Appl. Phys. 122, 025116 (2017).

[28] B. Saha, M. Garbrecht, J. A. Perez-Taborda, M. H. Fawey, Y. R. Koh, A. Shakouri, M. Martin-Gonzalez, L. Hultman, and T. D. Sands, Appl. Phys. Lett. 110, 252104 (2017).

[29] M. Zebarjadi, Z. Bian, R. Singh, A. Shakouri, R. Wortman, V. Rawat, and T. Sands, J. Electron. Mater. 38, 960 (2009).

[30] V. Rawat, Y. K. Koh, D. G. Cahill, and T. D. Sands, J. Appl. Phys. 105, 024909 (2009).

[31] S. Kerdsongpanya, B. Sun, F. Eriksson, J. Jensen, J. Lu, Y. K. Koh, N. V. Nong, B. Balke, B. Alling, and P. Eklund, J. Appl. Phys. 120, 215103 (2016).

[32] J. M. Gregoire, S. D. Kirby, M. E. Turk, and R. B. van Dover, Thin Solid Films 517, 1607 (2009).

[33] S. Kerdsongpanya, B. Alling, and P. Eklund, Phys. Rev. B 86, 195140 (2012).
[34] G. D. Mahan and J. O. Sofo, Proc. Natl. Acad. Sci. USA 93, 7436 (1996).

[35] B. Saha, J. A. Perez-Taborda, J.-H. Bahk, Y. R. Koh, A. Shakouri, M. Martin-Gonzalez, and T. D. Sands, Phys. Rev. B 97, 085301 (2018).

[36] J. F. Ziegler, software SRIM, version 2013.00, http://www.srim.org/.

[37] G. Greczynski, D. Primetzhofer, J. Lu, and L. Hultman, Appl. Surf. Sci. 396, 347 (2017).

[38] C. Frétigny, J.-Y. Duquesne, D. Fournier, and F. Xu, J. Appl. Phys. 111, 084313 (2012).

[39] C. Frétigny, J. P. Roger, V. Reita, and D. Fournier, J. Appl. Phys. 102, 116104 (2007).

[40] B. Li, J. P. Roger, L. Pottier, and D. Fournier, J. Appl. Phys. 86, 5314 (1999).

[41] L. Pottier, Appl. Phys. Lett. 64, 1618 (1994).

[42] See Supplemental Material at http://link.aps.org/supplemental/ 10.1103/PhysRevB.98.205307 for more information and confirmation of the different observations using other techniques, such as XPS, electrical conductivity at low temperature, and the HAADF elemental map of the samples. Full details of the thermal conductivity measurement, fit, and model used for this paper are also presented. This can also bring another view of the same data collected with the same techniques but plotted differently (thermoelectric properties). The Supplemental Material contains Refs. [18,19,25,38-41,46,52-56].

[43] B. Saha, G. Naik, V. P. Drachev, A. Boltasseva, E. E. Marinero, and T. D. Sands, J. Appl. Phys. 114, 063519 (2013).

[44] L. Porte, J. Phys. C 18, 6701 (1985).

[45] H. A. H. Al-Brithen, E. M. Trifan, D. C. Ingram, A. R. Smith, and D. Gall, J. Cryst. Growth 242, 345 (2002).

[46] M. A. Moram, Z. H. Barber, and C. J. Humphreys, Thin Solid Films 516, 8569 (2008).

[47] D. Gall, I. Petrov, L. D. Madsen, J.-E. Sundgren, and J. E. Greene, J. Vac. Sci. Technol. A 16, 2411 (1998).

[48] A. 1. Febvrier, N. Tureson, N. Stilkerich, G. Greczynski, and P. Eklund, J. Phys. D: Appl. Phys. 52, 035302 (2019).

[49] S. Kerdsongpanya, O. Hellman, B. Sun, Y. K. Koh, J. Lu, N. Van Nong, S. I. Simak, B. Alling, and P. Eklund, Phys. Rev. B 96, 195417 (2017).

[50] E. Rimini, Ion Implantation: Basics to Device Fabrication (Springer, New York, 2013).

[51] J. M. Ziman, Electrons and Phonons: The Theory of Transport Phenomena in Solids, International series of monographs on physics (Clarendon, Oxford, 1960).

[52] A. M. Hofmeister, Phys. Chem. Miner. 41, 361 (2014).

[53] J. F. Shackelford and W. Alexander, CRC Materials Science and Engineering Handbook, 3rd ed. (CRC, Boca Raton, FL, 2000).

[54] N. Ye, The interfacial thermal conductance of epitaxial metalsemiconductor interfaces, Ph.D. thesis, University of Delaware, 2017.

[55] W. Jaber and P.-O. Chapuis, AIP Advances 8, 045111 (2018).

[56] S. Kasap, C. Koughia, H. Ruda, and R. Johanson, in Springer Handbook of Electronic and Photonic Materials, edited by S. Kasap and P. Capper (Springer, Boston, 2007), p. 19. 